\title{
Incidental Synovial Myxoma with Extensive Intermuscular Infiltration in a Dog
}

\author{
Takeshi IZAWA ${ }^{1) *}$, Miyuu TANAKA ${ }^{1)}$, Mika AOKI ${ }^{2)}$, Fumihito OHASHI ${ }^{2)}$, Jyoji YAMATE ${ }^{1)}$ and \\ Mitsuru KUWAMURA ${ }^{1)}$ \\ ${ }^{1)}$ Laboratory of Veterinary Pathology, Osaka Prefecture University, Rinku-Orai Kita, Izumisano, Osaka 598-8531, Japan \\ ${ }^{2)}$ Laboratory of Veterinary Surgery, Osaka Prefecture University, Rinku-Orai Kita, Izumisano, Osaka 598-8531, Japan
}

(Received 9 May 2012/Accepted 23 June 2012/Published online in J-STAGE 6 July 2012)

ABSTRACT. A 16-year-old male mixed-breed dog was euthanized due to progression of renal failure caused by renal adenocarcinoma in the left kidney. Apart from main symptomatic lesion, accumulation of transparent jelly-like fluid was observed between the right femoral muscles. Gross examination of the right hindlimb revealed multiple nodules in the articular surface and capsule of the stifle joints, which extended into the crural muscles. Histopathologically, the joint and intermuscular masses were characterized by variously-sized hypocellular nodules consisting of spindle to stellate cells suspended in an abundant myxoid matrix. There were cystic structures within the intermuscular masses, lined by synoviocyte-like cells. Based on the gross and histopathologic findings, the case was diagnosed as synovial myxoma with extensive intermuscular infiltration. Synovial myxoma should be considered in the differential diagnosis of dogs with myxomatous tumor between skeletal muscles, even in absence of joint or muscle symptoms.

KEY WORDS: canine, intermuscular infiltration, stifle, synovial myxoma.

doi: 10.1292/jvms.12-0207; J. Vet. Med. Sci. 74(12): 1631-1633, 2012

Synovial myxoma is a unique lesion of the synovium and one of the most common joint tumors in dogs, especially large-breed middle-aged dogs [1-3]. They are characterized by myxomatous nodules protruding into the joint cavity, with proliferation of cells resembling both type A and B synoviocytes; the cellular origin of the tumor is still undetermined. Synovial myxoma has a good prognosis with long survival time, even with incomplete excision of the tumor [3]. Local recurrence is rare, and metastasis has not been reported. They sometimes invade the bone and extend beyond the joint capsule, infiltrating along fascial planes of adjacent muscles [3, 4]. However, the histopathology of the muscle infiltration of the tumor has not been well described. Here, we report a synovial myxoma of the right stifle with extensive intermuscular infiltration in an aged dog with lack of clinical signs of joint disease.

A 16-year-old male mixed-breed dog (body weight: 17.8 $\mathrm{kg}$ ) developed renal failure and had received corticosteroid therapy for 6 months at the Veterinary Medical Center at Osaka Prefecture University. Ultrasonography revealed a mass in the left kidney. The dog was euthanized because of poor clinical condition. At necropsy, a $3 \times 3 \times 4 \mathrm{~cm}$ firm, whitish mass was observed in the left kidney (histopathologically diagnosed as renal adenocarcinoma). Accumulation of transparent jelly-like fluid was observed between the right femoral muscles. A detailed examination of the right hindlimb revealed soft translucent nodules up to $7 \mathrm{~mm}$ in diameter in the articular surface and capsule of the femo-

\footnotetext{
*Correspondence to: Izawa, T., Laboratory of Veterinary Pathology, Osaka Prefecture University, Rinku-Orai Kita, Izumisano, Osaka 598-8531, Japan.

e-mail: izawa@vet.osakafu-u.ac.jp

(C)2012 The Japanese Society of Veterinary Science
}

ropatellar and femorotibial joints. Similar nodules were observed between the crural muscles (cranial tibial muscle, long digital extensor muscle and lateral digital extensor muscle). There were some cysts filled with mucinous fluid within the intermuscular masses (Fig. 1, arrow).

The joint and intermuscular masses were fixed in $10 \%$ neutral-buffered formalin, embedded in paraffin and cut at 5 $\mu \mathrm{m}$. Sections were stained with hematoxylin and eosin (HE) and alcian blue. Immunohistochemistry was performed for vimentin (clone V9; Dako, Glostrup, Denmark), cytokeratin (clone AE1/AE3; Dako), macrophage scavenger receptor (CD204; clone SRA-E5; Transgenic, Kumamoto, Japan), proliferating nuclear cell antigen (PCNA; clone PC10; Dako) and Ki-67 (clone MIB-1; Dako). SRA-E5 antibody recognizes a broad range of macrophages in normal and diseased tissues of the dog [6].

Histologically, the joint masses were characterized by variously-sized hypocellular nodules consisting of spindle to stellate cells suspended in an abundant myxoid matrix (Fig. 2). The myxomatous stroma within the nodules stained positively with alcian blue. The intra-articular portions of the masses were covered with synovium. There was no invasive growth into bone. Similar myxomatous nodules were observed in the fascial planes of the crural muscles, with lack of intramuscular infiltration (Fig. 3). There was no evidence of muscle injury; only a small number of muscle cells were atrophied due to compression by the nodules. The cysts within the intermuscular masses were lined by a single to a few layers of round cells resembling synovial cells (Fig. 4). The spindle to stellate cells within the myxomatous nodules of the joint and intermuscular masses, cyst-lining cells in the intermuscular masses, and synovial cells in the joint masses were strongly positive for vimentin (Fig. 5) and negative for cytokeratin. Some of the cyst-lining cells and large round cells in the myxomatous nodules were positive 


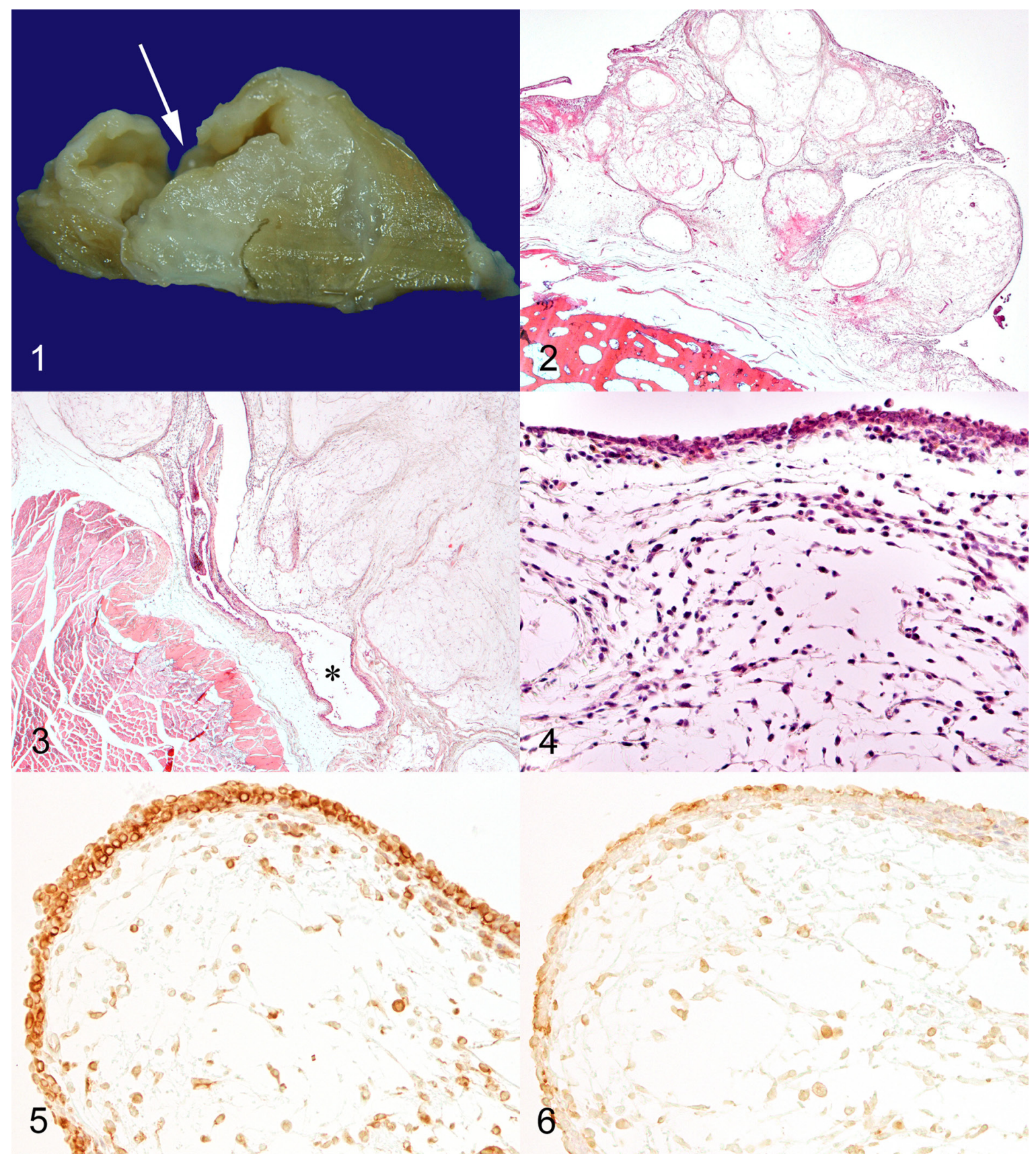

Fig. 1. Crural muscle; dog. Intermuscular mass after formalin fixation. Arrow indicates a cystic structure within the mass.

Fig. 2. Stifle; dog. The joint mass consisting of variously-sized myxomatous nodules protruding into the joint cavity without bony invasion. HE.

Fig. 3. Crural muscle; dog. The intermuscular mass consisting of multiple myxomatous nodules with cystic structure (asterisk). Note the lack of neoplastic infiltration of the adjacent muscle. HE.

Fig. 4. Crural muscle; dog. The cystic structure within the mass is lined by round to cuboidal cells resembling synoviocytes. HE.

Fig. 5. Crural muscle; dog. The cyst-lining cells, and cells in the myxomatous nodule are positive for vimentin. Immunoperoxidase method counterstained with hematoxylin.

Fig. 6. Crural muscle; dog. Some of the cyst-lining cells and round cells in the myxomatous nodule are positive for macrophage scavenger receptor (CD204). Immunoperoxidase method counterstained with hematoxylin. 
for macrophage scavenger receptor (Fig. 6). A small number of the cyst-lining cells and spindle to stellate cells within the myxomatous nodules stained positively for PCNA (positive rate: 2.7 and $2.8 \%$, respectively), while none of the cells stained for Ki-67. Renal adenocarcinoma was confined to the left kidney; no metastasis was detected.

The gross and histopathologic findings of the joint and intermuscular masses were consistent with those of canine synovial myxoma [1-3]. Muscle infiltration of synovial myxoma has been reported in some cases $[3,4]$, but little is known about the histopathology of the muscle lesions. In the present study, we report for the first time the histopathologic findings of muscle lesions of synovial myxoma, including the cystic structures lined by synoviocyte-like cells. Canine synovial myxoma consists of spindle to stellate cells producing mucinous matrix (type B synoviocytes) and some CD18positive cells (type A synoviocytes) $[3,5]$. In the medical literature, type A and B synoviocytes are thought to represent functional modulations of the same cell, since both cell types express vimentin and CD68 [7]. In the present study, there was proliferation of both type A (cyst-lining cells) and $\mathrm{B}$ (spindle to stellate cells within myxomatous nodules) synoviocytes in the intermuscular masses, with no difference in PCNA positivity between the two types, suggesting that the presence of cyst lined by type A synoviocyte-like cells can be a key histopathologic finding for diagnosis of synovial myxoma in non-articular tissue.

Despite extensive infiltration of the synovial tumor into the adjacent skeletal muscles (crural and possibly femoral parts), the dog had no signs of lameness; accumulation of jelly-like fluid between the femoral muscles was only a necropsy finding indicating the hindlimb lesion. Histopathologic examination revealed that the adjacent muscle is likely intact, since the tumor does not extend beyond the fascial planes, which can result in the absence of muscle symptom in this case. Therefore, pathologists can encounter incidental synovial myxoma at necropsy as intermuscular myxoid mass in the dog.
This study reported synovial myxoma of the right stifle joint with extensive intermuscular infiltration in a dog as an incidental necropsy finding. Careful gross examination of the joint is indispensable for detection of subclinical synovial myxoma. Intermuscular infiltration of synovial myxoma should be considered in the differential diagnosis of dogs with myxomatous tumor between skeletal muscles. Cystic structures lined by type A synoviocyte-like cells with multiple myxomatous nodules can be a histologic hallmark of intermuscular synovial myxoma.

ACKNOWLEDGMENT. This work was supported in part by Grant-in-Aid for Young Scientists (B) from Japan Society for the Promotion of Science (JSPS; no. 24780288).

\section{REFERENCES}

1. Craig, L. E. 2011. Synovial tumours in dogs. N. Z. Vet. J. 59: 154. [CrossRef]

2. Craig, L. E., Julian, M. E. and Ferracone, J. D. 2002. The diagnosis and prognosis of synovial tumors in dogs: 35 cases. Vet. Pathol. 39: 66-73. [Medline] [CrossRef]

3. Craig, L. E., Krimer, P. M. and Cooley, A. J. 2010. Canine synovial myxoma: 39 cases. Vet. Pathol. 47: 931-936. [Medline] [CrossRef]

4. Pool, R. R. and Thompson, K. G. 2002. Myxoma of the synovium. pp. 213-214. In: Tumors in Domestic Animals, 4th ed. (Meuten, D. J. ed.), Iowa State Press, Iowa.

5. Thompson, K. 2007. Synovial joints. pp. 132-135. In: Jubb, Kennedy and Palmer's Pathology of Domestic Animals, 5th ed. (Maxie, M. G. ed.), Elsevier, Philadelphia.

6. Tomokiyo, R., Jinnouchi, K., Honda, M., Wada, Y., Hanada, N., Hiraoka, T., Suzuki, H., Kodama, T., Takahashi, K. and Takeya, M. 2002. Production, characterization, and interspecies reactivities of monoclonal antibodies against human class A macrophage scavenger receptors. Atherosclerosis 161: 123-132. [Medline] [CrossRef]

7. Weiss, S. W. and Goldblum, J. R. 2008. Benign tumors and tumor-like lesions of synovial tissue. pp. 769-788. In: Enzinger and Weiss's Soft Tissue Tumors, 5th ed., Mosby Elsevier, St. Louis. 